\title{
Researchers' Communities Face to the COVID-19 Pandemic, between Carrier Management and Decision Choice; the Bioethics may be the Solution
}

\author{
Bouchentouf Salim ${ }^{1,2, *}$, Benabdeli Kheloufi ${ }^{3}$ and Bouchentouf Amina \\ Angelika ${ }^{4}$ \\ ${ }^{1}$ University of Saida - Dr. Moulay Tahar Faculty of Technology, Algeria. \\ ${ }^{2}$ Laboratory of Natural and Bioactive Substances- University of Tlemcen, Algeria \\ ${ }^{3} \mathrm{Geo}$-Environement laboratory- Mustapha Stambouli University of Mascara, Algeria \\ ${ }^{4}$ Laboratory of Mathematics, Djillali Liabes University of Sidi Bel Abbes, Algeria
}

Short Communication

Volume 4 Issue 2

Received Date: November 16, 2020

Published Date: December 04, 2020

DOI: $10.23880 /$ phoa-16000167

*Corresponding author: Salim Bouchentouf, Faculty of Technology, Doctor Tahar Moulay University of Saida, Cite El Nasr, P.O. Box 138, Algeria, Tel: +213696423259; Email: bouchentouf.salim@yahoo.fr / salim.bouchentouf@univ-saida.dz

\section{Abstract}

After the Corona pandemic of 2019, many victims around the world will be left behind. Like many global epidemics, the 2019 corona virus is expected to leave behind great debate, greater geostrategic and political changes. International organizations seemed incapable of involving international scientific communities in a unified ethics in the face of the crisis. Since its onset, the disease has been denied, countries pirate medical supplies exported to other countries affected by the epidemic, and others flout universal ethics and morals. Today, it is extremely necessary to think about another vision of ethics to which the world must refer, whether at different cases of law, medical, scientific, political conflicts or other health problems.

Keywords: Covid-19; Ethic; Biomedical Research; Bioethics; New World Vision

\section{Introduction}

Habitually, exceptional circumstances and natural disasters raise many questions that are often uninhibited in times of capacity and prosperity. Although we encounter most of these questions as researchers during our studies, we treat them as intellectual luxury and exclude their occurrence. Faced with the Covid-19 pandemic, societies are not ready to undertake such a phenomenon for various societal, scientific, technical and religious reasons. The health sector in several so-called developing countries is known for its many organizational, material and professional lacunas. The fault lies with the whole society and in particular with politicians and parties who have supported the mismanagement of strategic sectors. The consequences and negative impacts of this clan management are real and present today. Faced with the Covid-19 pandemic, if the situation which seemed to be under control according to the managers of this file in many countries, the indicators contradict this assertion such as: The fault lies with the whole society and especially with politicians and parties which supported the mismanagement of strategic sectors. The consequences and negative impacts of this clan management are today real and present.

Faced to the Covid-19 pandemic, if the situation which seemed to be under control according to the managers of this file in many countries, the indicators contradict this assertion as:

- The number of daily contamination.

- The citizens' behavior in the face of this virulent virus. 


\section{Public Health Open Access}

- The quality of the bibs placed on the informal market.

- The celebration of weddings.

- The lack of vigilance and professionalism of people in charge of applying the instructions.

- The politicization of this epidemic through terse press releases.

On the other hand, the pandemic situation makes researchers and medical teams face to ethics and professional conduct questions to which they haven't the time to answer now. The scientific research sector is suffering greatly from this pandemic; because of on one hand researchers are under pressure to answer the myriad and diverse questions of politicians, citizens and their colleagues. On the other hand, researchers are constrained by the various restrictions imposed by the pandemic situation and the state of scientific research in which they suddenly found themselves unable to communicate and exchange. Face to the COVID-19 pandemic, many researchers fear that continuing to cancel conferences for a long period could have a detrimental effect, especially on students and researchers who are still in the early stages of their careers, because both groups depend on conferences to discuss their research found, find employment and publish their work. Many university experts around the world are calling for continued support to researchers, especially young researcher, to avoid long-term damage. Several specialists fear a "lost generation of researchers" which could result from the funding crisis caused by the new Corona virus.

Such warnings calls come as fears grow among $\mathrm{PhD}$ and postdoctoral students, who are struggling to complete their current research projects during containment. The crisis is not affecting only their research but also their potential future jobs. The situation of educational and research establishments seems critical. Reports in some countries indicate that researchers who have recently taken up their jobs will be the first scapegoats for any budget cuts. The reduction in research jobs would initially affect young researchers, including recent graduates, as well as researchers who have recently taken up their jobs, who have spent a few years in their work, and women at different stages [1-4].

In some countries there is optimism that research will regain its strength if funders can provide support quickly, but hundreds of universities have pushed for a recruitment stop by warning that new researchers will be the most affected. In this situation, Professor Simon Marginson of the University of Oxford in Great Britain says: "New researchers will have very few opportunities for funding and employment, while doctoral students will graduate towards a dead market". He adds: "There will be a lost generation of researchers unless we are very aware and smart about dealing with this crisis." Marginson warns that if the problem is not resolved, it will not be limited to the researchers themselves, their lives and their future aspirations, but that the research itself could be affected in number and quality in the long run. Scientific research and these researchers that world relies on to find a solution to pandemics and prevent future disasters are disturbed at the time when scientists are rushing to understand the new Corona virus (SARS-Cove-2) and contain the chaos that it caused, the virus epidemic created chaos within the scientific community itself. If in so-called developed countries the situation of researchers and research is critical, what shall we say about developing or underdeveloped countries?. With the increase in Covid-19 cases around the world due to an alleged second wave, gatherings of all kinds have started to be canceled or postponed after being tolerated. This includes tech developer conferences, book fairs, rock concerts, auto shows, and UN-sponsored Climate Week, as well as numerous scientific conferences, which are often fertile ground for new ideas and collaborative projects. At the same time, research institutions and government agencies began to impose increasingly stringent restrictions over time, preventing scientists from traveling internationally and nationally. Currently, many researchers have resorted to electronic meetings (and online academic studies). However, such alternatives cannot fully compensate what researchers have lost, because of personal gatherings are essential for collaborative projects, as well as large-scale projects $[5,6]$.

Researchers around the world face rules concerning their areas of expertise, but in biomedical research, the rule holds sway. After months of controversies relating to the methods of using a therapeutic protocol to treat patients with Covid-19, the questioning of a doctor and researcher before the ordinal authorities is increasingly mentioned nowadays. Because of in the same way as the prioritization in intensive care imposes fair and strict rules of eligibility for treatment, the research strategies that scientists put in place must fall within protocols that are mindful of the values involved, and follow methodologies referring to international standards. In a health crisis and emergency faced by researchers, certain principles may however be subject to derogations, if they are justified. The tension between research ethics, medical ethics and care makes it necessary to argue for delicate arbitration processes; otherwise the practice of the doctor could be called into question from an ethical point of view.

However, faced to situation such as we are living in, several questions arise: how to assess the methodological and decision-making criteria of biomedical research? Are we entitled to consider that the best interests of the community justify infringing the principles of respect for the individual and their rights, in particular by exposing them to risks which in current practice would prove to be ethically unacceptable? Is it conceivable that a "compassionate" approach could justify exceptional measures on the grounds 


\section{Public Health Open Access}

that the imperative would be "to do everything in order to avoid the worst"? The scientific approach is governed by rules that ensure its robustness. It is important that doctors' engagement with research teams allow mobilization that is essential to provide therapeutic responses to a pandemic threat. Scientific advances bear witness to researcher freedom ability to confront his intuitions to the test of experimentation, but also to contradictory hypotheses and theories. Scientific controversy attests the strength of scientific dynamics. It is also necessary to produce knowledge and incontestable results, because they are relevant, reproducible and backed by published studies with a concern for methodological rigor and data accuracy. Is travel bans, airports closure, places of worship, and markets morally justified? Are the social isolation and quarantine measures morally justified? And if they are justified, how can we make sure that the basic needs reach the people in this situation? How to avoid the stigmatization of people infected with the virus? What are the virtues that individuals should possess in the event of an epidemic, whether their movement or their consumption and storage of foods, or by volunteering to help health authorities if necessary, or in compliance with the instructions of competent authorities? If thinking about self-interest is an innate feeling, then what is the best behavior towards the poor and needy that goes through this day to day ordeal? If a person is infected with the virus, how should they act and should they notify the authorities? What should each person have to prevent the spread of the virus? And if he knew that another person was infected but not self-isolating, should he reports it first or advise him to notify the health authorities first?. And who doubts that they are infected, what should they do at the stage of doubt? Do they need to self-isolate immediately to be safe, or do they have to continue their normal life until confirmation of contamination? On another level: what research is now a priority at the time of epidemics? Should the state transparently disclose the spread of the disease to educate people about the dangers around them, or should the state reduce it under the guise of not creating panic among people?. We can discuss a lot in ethical questions in times of epidemics, which are questions that deal with the State, the individual and the group, but come back to two main things: "normative ethics" which assesses the actions which is their agent, and "the ethics of virtues" which focuses on the actor himself and his virtues, which is an earlier stage on verbs and embodied in them at the same time. If we go ahead with normative ethics, we find that it raises a lot of discussion. Because it deals with unlimited verbs and it relates to the intricacies of the relationship between religion, law and morals. In addition, epidemics impose on us exceptional behaviors that contradict the rights and provisions established by the matter under normal circumstances. Health policies, for example, tend to restrict the freedoms and movements of people, such as voluntary social isolation, the medical isolation of the sick and the quarantine of a city or region, which can include the sick, suspect and healthy together, all of which are measures that conflict with basic human rights and require moral justifications. So that it is based on solid principles and explanations.

For example, the closure of worship places has caused great controversy because of it is a question of worship. But most of the comments did not address the issue in an ethical approach, and this procedure was rarely linked to other gatherings and group events (cultural, sporting, etc.), because behind them is the same causes, and it is based on a specific medical diagnosis. Therefore, the discussion should have focused on discussing the cause itself and the extent of its achievement first, then on the effectiveness of such a procedure in achieving the goal, and then on the weighting between the values to be achieved, whether in the case of the preservation of collective activities including religious rituals even if in the case of canceling them. Collective activities are related to a set of values: the right to worship, freedom of movement and self-preservation, all of which are well-established rights of individuals, but also correspond to the moral responsibility of the state for health. public awareness of citizens, especially since such as danger expose the capacity of the State to vulnerability; This will affect its future and course, as has happened in many epidemics that have historically harvested groups of people and depleted the powers of the state, which has accelerated its political, economic and social collapse.

The field of ethics helps us to define the ethical principles and values that govern our actions in times of epidemics and infectious diseases, and it also helps us to formulate our priorities and our good choices between a set of actions. It also helps us to determine what is right or wrong, and provide the necessary justifications to do what is right is true or what is false. It's step by step, in an organized way in which coherence and rationality are achieved from the sources that a society takes for granted (religion, reason, custom ...). All of these ethical explanations are necessary if we would like to change the behavior of individuals and institutions. As long as we are talking about individuals who enjoy their freedom and independence. Jurisprudence in most states has defined cases of necessity and distinguished them by special provisions, but the state of emergency is more precise. It is the expression of an unfinished event, but it is still forming and we do not yet know its final form, and it requires dynamic activity, and it also requires rapidity in decision making. It is a state which practically tests the possibilities of harmonization between the principles and the higher values fixed in natural conditions and what is available or possible at the present time. The state of necessity is often a stable or static state. 


\section{Public Health Open Access}

In the normative ethics of actions, the definition of values and guiding principles and the balance between them is a central issue in the case of epidemics, we are talking about a set of values, including: the preservation of life and health, individual liberty and the justifications for restricting it, moral responsibility to oneself and to others, and state responsibility to Society, professional obligations of medical and other workers. The ethical point of view is based on the construction of the explanations necessary for the actions and the determination of the criteria on the basis of which the priorities are determined. Here a balance is made between the duties themselves, between the interests between them, between the evils among themselves, between interests and evils together, between minor and transgresses actions, between private and public, and between damage and damage, etc.

In public health ethics in times of epidemic, we are faced to a balance between two approaches: an approach that favors respect for the rights of individuals and does not restrict their freedom except to the extent necessary only, and a method that gives the highest priority to the interest of the group and the preservation of public health. But the opinion which is consistent with case law and the rules of interest is that the interest of the group advocates; especially since we are talking about exceptional measures which are limited by a specific circumstance which will cease to exist. An example of a problem in setting priorities is the answer to the question: Who should the medical team start with when it is necessary to choose due to lack of treatment equipment and insufficient medical teams? This question is addressed in the field of medical ethics and ethics of epidemiology particularly. Some of them found the opportunity to criticize the other side and prove that it is unethical to deal with patients, without seeking a serious discussion of the standard to be followed in this case and why? Should we prioritize the sickest? The most innocent? The youth? The most vulnerable groups such as the elderly and children? Or health workers?

Opinions differ, and there is no mutually agreed standard, and when there is no weight, the interest or the right is hidden and there are no arguments. Lawyers usually resort to the drawing of lots, so if the interest or the right is determined on one side, they do not allow the use of lots. It is an objective method to soften hearts and remove the accusation of partiality and prejudice, and they have applied it in many matters. But the example presented here, even if it is about an accident, it returns to old doctrinal questions and to debates on several subjects: what is done by "the vote", "the timidity of the others ", and" the passage from one cause of death to another ", which are all issues that concern the preservation of rights and the preservation of values or a comparison between them [7-11].
If the jurisprudential discussion is much devoted to the discourse of the individuals themselves and the necessary conditions such as having the capacity, for example, and presenting the closest and the closest to it when the tasks are overloaded, our discussion here is centered on the competent bodies that take responsibility for the timidity of people, whether medical teams or a Ministry of Health which sets public policies. It does not seem to us that the lottery works here as a method, because the choice between the patients in this case is based on conflicting interests which balance between them and are subjected to the rules of budgeting. We also speak about emergency ethics which requires a decision price based on a scientific vice, and not arbitrary. However, the fact remains that the choice here will undermine the value of justice and equality among patients to achieve equal access to the treatment needed, but this is not available given the prevalence of epidemics, which means that the capacity condition is not available.

\section{Discussion}

Discussions revolve around two criteria: the diagnosis of the disease and the degree of its need for treatment, and an estimate of the desired cure rate. The philosophy of duty (deontology)agreeswith the firstcriterion, and the philosophy of utilitarianism and consequences of action agrees with the second criterion. Regarding the central question of the criterion of choice, it is necessary to differentiate between two concepts: medicine and moderation (saving a life), and the lawyers who differentiate them according to the diagnosis of the person's condition and according to the assessment of the efficacy of the treatment itself which is assumed even if the degree of suspicion is varies. For those who oversee perdition, the treatment should be offered to those who are still in the early stages of the disease, and the criterion here is shyness and degree of need with no difference between the young and old, because of souls are have equal value, even an elderly person with other associated illnesses is the first to apply; this will double the likelihood that the person will die from illness, and therefore the severity of his need for treatment is urgent otherwise it is hopeless.

Against all of this it seems that ethical discussions are both necessary and rich, and that they are based on reasoning and the presentation of coherent arguments. In this context, bioethics can answer to several unresolved questions and enrich the debate by contributing new concepts. Interdisciplinary experts are trained to analyze ethical issues specific to the worlds of health (health care, public health). In these times of crisis, they are called upon to speak out on issues related to resource allocation or the quarantine of populations. They guide and criticize, when necessary, government initiatives. In doing so, they help journalists 
and the public to better understand the justifications and the limits of the various constraints to which we are subjected, such as the restriction of our freedoms in the name of the common good, and the challenges that our societies currently face. However, even though bioethics has been around for more than 50 years, this area of study and professional practice remains little known to the general public. Bioethicists are experts in applied ethics who can come from several disciplines (philosophy, social sciences, law, medicine, nursing, and sciences). Interdisciplinary is one of the pillars of this field. Although they are often seen as thinkers feeding off big theories, they can also be called upon to strongly criticize unethical practices or decisions. Sometimes a safeguard, sometimes a mediator, and sometimes a critic, the bioethicist undertakes multiple roles, where the common point is to ensure the maintenance of the values and ethical principles of our societies such as responsibility, justice, beneficence, solidarity, transparency, respect for autonomy, human dignity, etc.

Bioethicists also ensure the protection of participants and the proper conduct of research as advisers to research ethics boards. However, with the Covid-19 pandemic, the emergency comes up against the usual rules of research. The world needs treatment and a fast vaccine, but clinical research in this context raises a host of ethical issues. Obviously, it is important that the research proceed in short time, but this requires rigor and increased monitoring, as any failure would not only result in wasted time, but also in serious risks and consequences for participants. Bioethicists must therefore ensure compliance with ethical standards and conduct, and also taking into account the risk of moving too slowly in a context of health crisis $[12,13]$.

The academic bioethicist, for his own part, can act as a thinker, trainer and guide to raise awareness, by analyzing and criticizing the issues related to major social issues. He retains his academic freedom, which allows him to take a critical look at social and political decisions, for instance, the government's lack of transparency on its various lockdown scenarios, or the use of smart phone applications and ascertaining in order to identify and track individuals and isolate contagious persons. In government organizations or in the health system, bioethicists, as public employees, do not have the same freedom of expression. However, they must answer to specific questions and play the role of guide and safeguard in their institutions. In the current crisis, they must quickly react and provide relevant decisionmaking frameworks (for instance, to manage moral distress or for triage) to guide and facilitate the implementation of intervention plans that will be both effective and ethical.

The COVID-19 pandemic has revealed the importance, the diversity and the relevance of bioethics. This profession reveals in turns to be a complex and interdisciplinary mosaic. What may sound like barriers are in fact bridges connecting the entire profession indeed, bioethicists play a supporting and catalytic role in guiding all the parties with which they interact, while maintaining their critical thinking in the service of society $[14,15]$.

\section{References}

1. (2008) Law And Bioethics. Oxford University Press, Oxford.

2. Akkermans J, Richardson J, Kraimer M (2020) The Covid-19 crisis as a career shock: Implications for careers and vocational behavior. Journal of Vocational Behavior 119: 103434.

3. Brody B (1998) The Ethics of Biomedical Research. Oxford University Press.

4. Everett J, Colombatto C, Chituc V, Brady W, CrockettM (2020) The effectiveness of moral messages on public health behavioral intentions during the COVID-19 pandemic. PsyArXiv Preprints.

5. Flood C, MacDonnell V, Theriault S, Venkatapuram S, Philpott J (2020) Vulnerable: The Law, Policy and Ethics of COVID-19, pp: 1-649.

6. Hayry M, Herissone KP, Takala T (2007) Ethics In Biomedical Research: International Perspectives.

7. Klugman CM (2020) What is a Bioethics of the Oppressed in the Age of COVID-19?. The American Journal of Bioethics 20(10): 29-31.

8. Lewis M, Tamparo C, Tatro B (2012) Medical Law, Ethics, \& Bioethics for Health Professions, $7^{\text {th }}$ (Edn.), FA Davis, Philadelphia, pp: 256.

9. Loewy E, Loewy R (2002) Changing Health Care Systems from Ethical, Economic, and Cross Cultural Perspectives. Springer, Netherlands.

10. McGuire A, Aulisio M, Davis F, Erwin C, Harter T, et al. (2020) Ethical Challenges Arising in the COVID-19 Pandemic: An Overview from the Association of Bioethics Program Directors (ABPD) Task Force. Am J Bioeth 20(7): 15-27.

11. Rosenbaum L (2020) Facing Covid-19 in Italy - Ethics, Logistics, and Therapeutics on the Epidemic's Front Line. N Engl J Med 382(20): 1873-1875.

12. Strech D, Mertz M (2016) Ethics and Governance of Biomedical Research. Springer. 
13. Suleman M (2020) Islam and Biomedical Research Ethics. Routledge, pp: 242.

14. Townsend R, Eburn M (2020) COVID-19- Legal and ethical implications for your practice. Australasian
Journal of Paramedicine 17: 3.

15. Ulrich C, Anderson E, Walter J (2020) COVID-19: Advancing Empirical Bioethics Research. AJOB Empir Bioeth 11(3): 145-147. 